\title{
Vibration Analysis of a Small Wind Turbine Blade
}

\author{
Ganesh B. Taware $^{\# 1}$, Sham H. Mankar ${ }^{\# 2}$, V. B. Ghagare ${ }^{\# 3}$, G. P. Bharambe ${ }^{\# 4}$, Sandip A. Kale ${ }^{\# 5}$ \\ "Trinity College of Engineering and Research, Pune, India \\ 'ganeshtaware11@gmail.com, \\ 2shm9176@gmail.com, \\ 3vbghagare@gmail.com, \\ 4ganvima@gmail.com, \\ 5sakale2050@gmail.com
}

\begin{abstract}
Composite materials have various complicated characteristics according to use of the constituent materials and boundary conditions. Therefore, it is difficult to analyze properties of composite materials. The composite materials are well known by their excellent combination of high structural stiffness and low weight. Their anisotropy allows the designer to tailor the material in order to achieve the desired performance requirements. Thus, it is necessary to develop tools that allow the designer to obtain designs, considering the structural requirements and functional characteristics. For efficient use of composite materials in engineering applications, the dynamic behavior (i.e. natural frequencies) should be known. This paper focuses on the behavior of small wind turbine blades manufactured from composite materials. Two small wind turbine blades are manufactured from the Glass Fiber Reinforced Plastic (GFRP) and GFRP with steel wire mesh reinforcement. Finite Element Analysis (FEA) was carried out by using finite element software ANSYS 16.0. From FEA theoretical natural frequencies and mode shapes of blades manufactured from the GFRP and GFRP with steel wire mesh reinforcement were obtained. Experimental free vibration test of manufactured blades were carried out to find the practical natural frequencies and mode shapes. Finally the results obtained from the FEA and experimental test for the blade manufactured from GFRP and GFRP with steel wire mesh are compared.
\end{abstract}

Keywords - Composite material, FEA, GFRP, Natural frequencies, Wind turbine blade

\section{INTRODUCTION}

Vibration is a mechanical phenomenon whereby oscillations occur about an equilibrium point. More often, vibration may be undesirable and wasting energy. Careful designs usually minimize unwanted vibrations. Vibration analysis is used to find early cause to machine failure, allowing machinery to be repaired before an expensive failure occurs. Modal analysis is the study of the modal parameters of structures under vibration excitations [1]. The goal of modal analysis in structural mechanics is to determine the natural mode shapes and frequencies of an object or structure during free vibration. It is beneficial to use the finite element method (FEM) to perform this analysis because, the object being analyzed can have irregular shape and the results of the calculations are acceptable [2]-[5].

An E-glass/epoxy composite blade for a horizontal axis wind turbine was designed and analyzed by Zhang Lanting [6]. Ashwani Kumara et al. worked to introduce a new material i.e. Al 2024 for wind turbine blades. The main part of this research was to identify natural frequencies and natural vibration modes of the $\mathrm{Al} 2024$ wind turbine blade [7].

GFRP composites are the cheapest and the most widely used for wind turbine blades. One of the latest innovations is to use thermoplastics as a material for matrix production in the form of woven fabric from lowpriced polypropylene and glass fibers. Mostly, a laminated composite beam is preferred for various engineering applications on priority. These beams are subjected to different environments and loads during their operation. Sometimes these beams exhibit irregular behavior under certain working condition. Hence, dynamic analysis of composite components is important to avoid the failure of the component, which can be analyzed by the natural frequency and mode shape [8]-[12].

In present work, the small wind turbine blades were manufactured from composite material GFRP and GFRP with steel wire mesh. The vibration analysis of these manufactured blades was carried out for finding natural frequencies and mode shapes. The change in natural frequencies was observed. 


\section{A. Material Selection}

\section{MATERial For Wind TURBine BLAde}

The primary requirements for blade materials are high stiffness to ensure aerodynamic performance, low density to minimize mass and long fatigue cycles. In the wind turbine industry, many materials have been used for blades, like metals, plastics, wood and composites. In this work the GFRP and GFRP with steel wire mesh was used for manufacturing the wind turbine blade. E-glass composites mat sheets such as $1 \mathrm{M}, 5 \mathrm{M}, 7 \mathrm{M}$ and RP 10 in different numbers in full and half sizes were used in hand layup process. The one layer of steel mesh having designation $16 \times 30$ is reinforced in GFRP while manufacturing the wind turbine blade. Two blades were manufactured, one from the GFRP and other from GFRP reinforced with steel wire mesh.

B. Properties of the material

The Table 1 gives the properties of Glass Fiber Reinforced Plastic material used for making these two blades,

TABLE 1. PROPERTIES OF GFRP

\begin{tabular}{|c|l|c|}
\hline Sr. No. & \multicolumn{1}{|c|}{ Properties } & Values \\
\hline 1 & Tensile modulus along X direction $(\mathrm{MPa})$ & 14000 \\
\hline 2 & Tensile modulus along Y direction $(\mathrm{MPa})$ & 6030 \\
\hline 3 & Tensile modulus along Z direction $(\mathrm{MPa})$ & 1530 \\
\hline 4 & Shear modulus along XY direction $(\mathrm{MPa})$ & 2433 \\
\hline 5 & Shear modulus along YZ direction $(\mathrm{MPa})$ & 1600 \\
\hline 6 & Shear modulus along ZX direction $(\mathrm{MPa})$ & 2433 \\
\hline 7 & Poisson ratio along XY direction & 0.217 \\
\hline 8 & Poisson ratio along YZ direction & 0.366 \\
\hline 9 & Poisson ratio along ZX direction & 0.217 \\
\hline 10 & Mass density of the composite $\left(\mathrm{kg} / \mathrm{mm}^{3}\right)$ & $2.23 \times 10^{-6}$ \\
\hline
\end{tabular}

III. Manufacturing OF THE BLADES

For manufacturing of blade hand layup process was used as shown in Fig.1. The mould shows the attachment of male-female block for perfect matching and also having a recess for squeezing the extra material out. Then mould is prepared for the manufacturing. Preparing a mould need to apply the wax polish, apply PV on the surface and then apply gel coat epoxy layer on surface.

After applying these three layers it was soaked for 30 minutes and then laid down the first surface of the mat. The surface mat offers a good surface finish. After that different decided mats of E- glass epoxy were layered on each other by using the resin. By using this process first blade was manufactured. For the second blade, above procedure is repeated for the decided combination of mats with addition of steel wire mesh at middle of the blade.

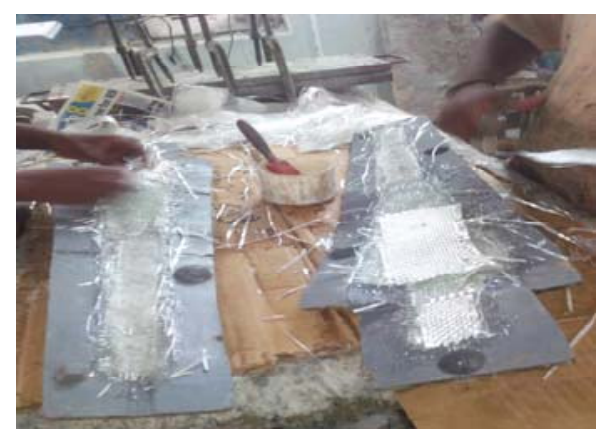

Fig. 1 Manufacturing of the blade 


\section{Computational Analysis of Blade}

For this work a $600 \mathrm{~mm}$ long, optimized blade having NACA 4412 profile, manufactured by Kale and Verma, is considered [13]. The modeling of blade was done using CATIA V5 software as shown in Fig. 2. For the analysis purpose ANSYS 16.0 software was used. The modal analysis is done for both the blades. Fine mesh type was used for meshing. The number of nodes obtained after meshing for GFRP blade were 3,32,925 and for GFRP with steel wire mesh were 5,77,474.

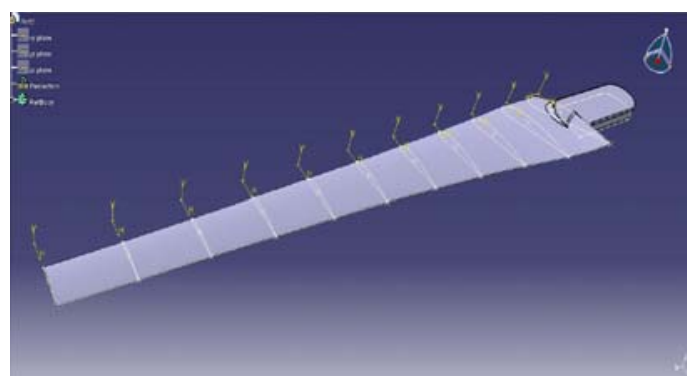

Fig. 2 CAD model for blade

Boundary conditions used for analysis are that the blade root is fixed and tip of the blade is free. Following are the first three natural frequencies in Hertz, obtained from the modal analysis.

TABLE 2. FIRST THEREE NATURAL FREQUENCIES (BY ANSYS)

\begin{tabular}{|c|c|c|}
\hline Mode No. & GFRP Blade & GFRP blade with steel mesh \\
\hline 1 & 6.67 & 6.78 \\
\hline 2 & 26.72 & 27.14 \\
\hline 3 & 41.09 & 41.90 \\
\hline
\end{tabular}

A. Mode shape plots

Following are the mode shape plots for first three natural modes of vibrations,

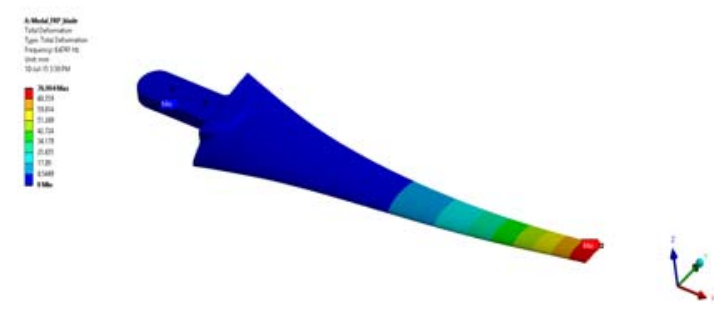

Fig. 3(a) First mode shape for GFRP blade

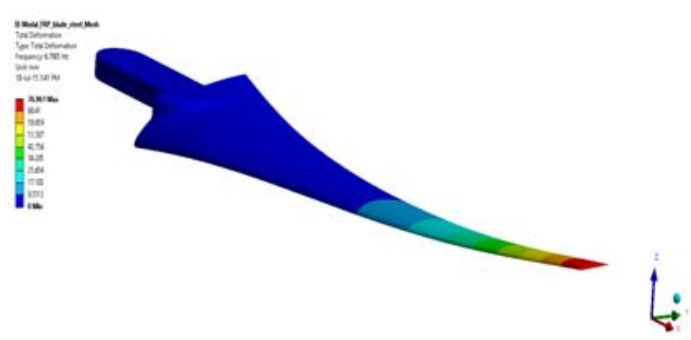

Fig. 3(b) First mode shape for GFRP blade with mesh 


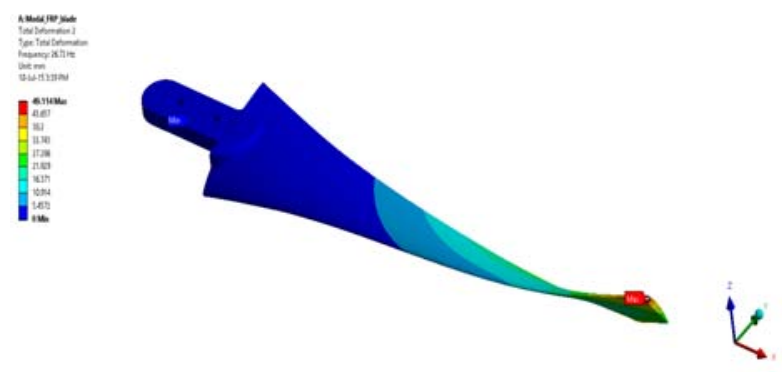

Fig. 4(a) Second mode shape for GFRP blade

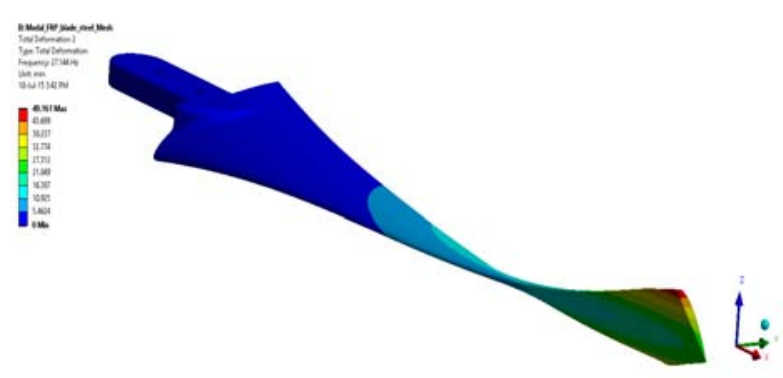

Fig. 4(b) Second mode shape for GFRP blade with mesh

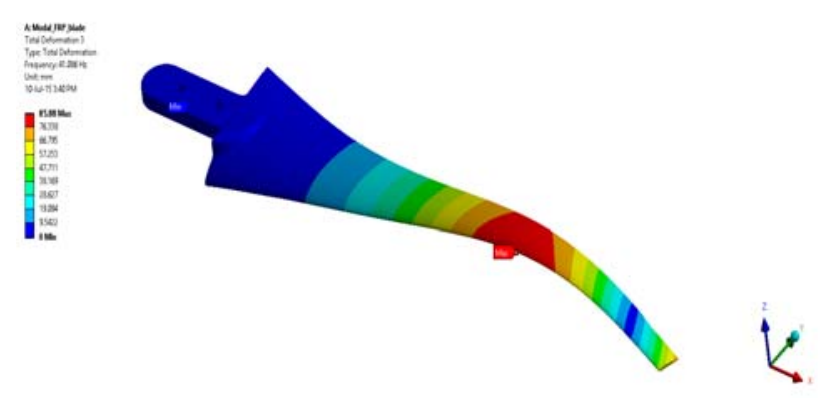

Fig. 5(a) Third mode shape for GFRP blade

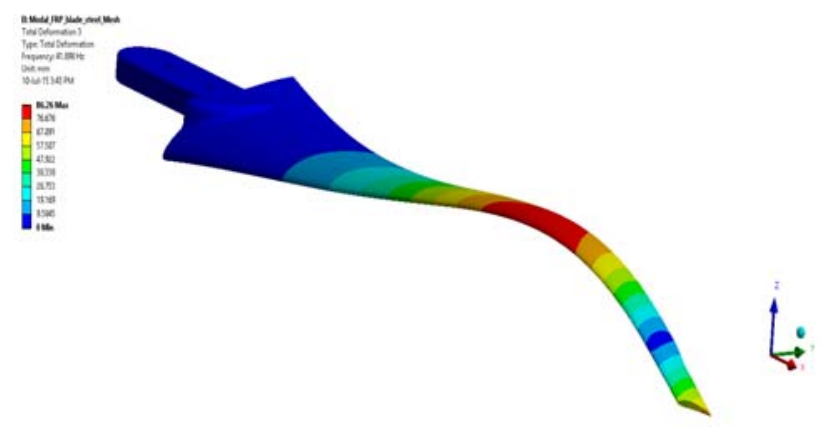

Fig. 5(b) Third mode shape for GFRP blade with mesh 


\section{EXPERIMENTAl ANALysis}

The experimental modal analysis was carried out for the blades manufactured from GFRP and GFRP with steel wire mesh. VA4Pro A4400 FFT analyzer was used for experimental analysis. The experimental setup is shown in Fig.6.

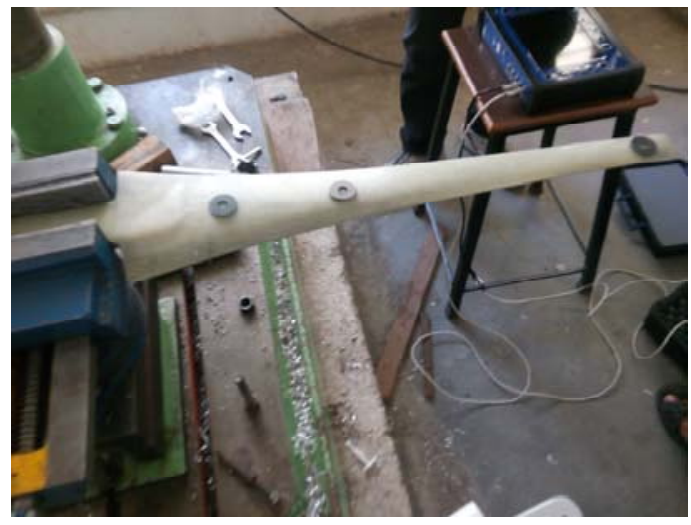

Fig. 6 Experimental setup

The result obtained from experiments as follows,

TABLE 3. FIRST THREE NATURAL FREQUENCIES (BY FFT)

\begin{tabular}{|c|c|c|}
\hline Mode No. & GFRP Blade & GFRP blade with steel mesh \\
\hline 1 & 7.14 & 8.12 \\
\hline 2 & 29.28 & 29.96 \\
\hline 3 & 44.14 & 45.22 \\
\hline
\end{tabular}

VI. RESULT AND DisCUSSION

The results were obtained from computational analysis and experiments for both the blade. The comparision of first three natural frequencies between GFRP blade and GFRP blade with steel wire mesh was carried out. The comparision is shown in Table 4 and Table 5,

TABLE 4 COMPARISION FOR ANSYS RESULT

\begin{tabular}{|c|c|c|c|c|}
\hline Mode No. & GFRP Blade & $\begin{array}{c}\text { GFRP blade with } \\
\text { steel mesh }\end{array}$ & $\begin{array}{c}\text { Increase in } \\
\text { frequency }\end{array}$ & $\begin{array}{c}\text { \% Increase in } \\
\text { frequency }\end{array}$ \\
\hline 1 & 6.67 & 6.78 & 0.11 & 1.59 \\
\hline 2 & 26.72 & 27.14 & 0.42 & 1.59 \\
\hline 3 & 41.09 & 41.90 & 0.81 & 1.98 \\
\hline
\end{tabular}

TABLE 5 COMPARISION FOR FFT RESULTS

\begin{tabular}{|c|c|c|c|c|}
\hline Mode No. & $\begin{array}{c}\text { GFRP } \\
\text { Blade }\end{array}$ & $\begin{array}{c}\text { GFRP blade } \\
\text { with steel mesh }\end{array}$ & $\begin{array}{c}\text { Increase in } \\
\text { frequency }\end{array}$ & $\begin{array}{c}\text { \% Increase in } \\
\text { frequency }\end{array}$ \\
\hline 1 & 7.14 & 7.42 & 0.28 & 3.92 \\
\hline 2 & 29.28 & 29.96 & 0.68 & 2.32 \\
\hline 3 & 44.14 & 45.22 & 1.08 & 2.45 \\
\hline
\end{tabular}

From Table 4 and Table 5, it can be seen that there is $2-3 \%$ increase in natural frequencies of wind turbine blade. The cause for increase in frequency is due to reinforcement of one layer of steel wire mesh in GFRP. Also from the mode shapes obtained from ANSYS shows that there is small variation in deformation of mode shapes. 


\section{VII.CONCLUSION}

A comparative study has been made among the GFRP blade and GFRP blade with steel wire mesh with respect to natural frequencies and deformation of mode shape. It is observed that the natural frequencies for first three modes of GFRP blade with steel mesh increases by 2-3 \% than the GFRP blade. Also, the mode shapes for first three modes showing that there is less variation in deformation of GFRP blade and GFRP blade with steel wire mesh. The natural frequencies obtained give the resonant condition frequencies for both the blades.

\section{REFERANCES}

[1] Mechanical Vibration, S. S. Rao, 2006, Pearson Prentice Hall; $4^{\text {th }}$ Revised edition.

[2] Mohammad Vaziri, Ali Vaziri, S. S. Kadam, "Vibration Analysis of Cantilever Beam by using F.F.T. Analyser", International Journal of Advanced Engineering Technology, E-ISSN 0976-3945.

[3] Mark H. Richardson, "Is It a Mode Shape, or an Operating Deflection Shape", Sound and Vibration Magazine, $30^{\text {th }}$ Anniversary issue, March 1997.

[4] Experimental Modal Analysis, Brian J. Schwarz \& Mark H. Richardson, Vibrant Technology, Inc. Jamestown, California 95327, pp. 12.

[5] Modal Testing of A Simplified Wind Turbine Blade, Tartibu, L.K., Kilfoil, M. And Van Der Merwe, A.J., International Journal of Advances in Engineering \& Technology, July 2012, pp. 1,11.

[6] Research on Structural Lay-up Optimum Design of Composite Wind Turbine Blade, Zhang Lanting, Energy Procedia 14, 2012, pp. $637-642$.

[7] Ashwani Kumara, Arpit Dwivedia, Vipul Paliwala, Pravin P Patilb, "Free Vibration Analysis of Al 2024 Wind Turbine Blade Designed for Uttarakhand Region Based on FEA”, Procedia Technology 14, 2014, 336 - 347.

[8] Maskepatil L.P.,Gandigude A.U., Kale S.A., "Selection of material for wind turbine blade by analytic hierarchy process (AHP) method ", Applied Mechanics and Materials, Volume - 612, pp. 145-150.

[9] Sandip A. Kale, Swanand R. Kulkarni, Suraj D. Shravagi and Ganesh P. Bharambe, "Materials for Small Wind Turbine Blades", Chapter 3, Renewable Energy and Sustainable Development , ISBN: 978-1-63463-464-9, 2015, pp. 43-54.

[10] Optimization Design, Modeling and Dynamic Analysis for Composite Wind Turbine Blade, Fangfang Songa, Yihua Nia and Zhiqiang Tanb, Procedia Engineering 16, 2011, pp. 369 - 375.

[11] John Delmonte, "Historical Perspectives of Composites”, International Encyclopedia of Composites, New York: VCH Publishers, 1990.

[12] Strong, A. Brent, Dearborn, "Fundamentals of Composites Manufacturing”, MI: Society of Manufacturing Engineers, 1989.

[13] Sandip Achutrao Kale, Ravindra N. Varma, "Aerodynamic Design of a Horizontal Axis Micro Wind Turbine Blade Using NACA 4412 Profile”, Vol 4, No 1 (2014), pp. 69-72. 